\title{
PENGARUH KONFLIK KERJA DAN STRES KERJA TERHADAP KINERJA KARYAWAN PT POS INDONESIA (Persero) BENGKULU 38000
}

\author{
Endi Pratama Erwandari \\ Anggri Puspita Sari \\ Program Studi Manajemen \\ Fakultas Ekonomi Dan Bisnis Universitas Bengkulu
}

\begin{abstract}
This research aims to know the effect of work conflicts and working pressure toward employees' performance of PT.Pos Indonesia (Persero) Bengkulu 38000. This research was an explanatory research by using quantitative research. Sample of this research was all of the population of the PT.Pos Indonesia (Persero) Bengkulu 38000 employee with total sample was 103 employee. To know the validity of the data, the researcher used validity and reliability of instrument. Meanwhile, to analyze the data, the researcher used double linier regression. Based on the result of analysis data, the researcher found that 1) concurrently work conflicts and working pressure give significant positive effect toward the employees' performance of PT.Pos Indonesia (Persero) Bengkulu. 2) Partially work conflicts give significant positive effect toward the employees' performance of PT.Pos Indonesia (Persero) Bengkulu. 3) Partially working pressure give significant positive effect toward the employees' performance of PT.Pos Indonesia (Persero) Bengkulu.
\end{abstract}

Keywords: Work Conflicts, Working Pressure, and Performance.

\section{PENDAHULUAN}

\section{Latar Belakang}

Kinerja adalah tingkat keberhasilan yang dicapai seseorang untuk mengetahui sejauh mana seseorang mencapai kinerja yang diukur atau dinilai. Kinerja karyawan didalam suatu organisasi tidak selalu mengalami peningkatan, terkadang kinerja karyawan mengalami penurunan. Upayaupaya untuk peningkatan kinerja karyawan dapat dilakukan dengan meneliti 
dan mengkaji sejauh mana faktor-faktor yang dapa memberikan pengaruh terhadap kinerja karyawan. Salah satu faktor yang dapat mempengaruhi kinerja adalah konflik kerja dan stres kerja. Konflik kerja dan stres kerja yang dialami oleh seseorang karyawan dapat berdampak pada kinerja karyawan.

Perilaku karayawan yang menyimpang dalam bekerja merupakan salah satu bentuk stress kerja. Stres kerja sebagai suatu kondisi ketegangan yang mempengaruhi emosi, proses berpikir dan kondisi seorang pekerja.Konflik kerja dan Stres kerja karyawan dapat berpengaruh pada kinerja karyawan, kinerja karyawan merupakan hal yang penting dalam pengembangan perusahaan. PT Pos Indonesia merupakan Badan Usaha Milik Negara (BUMN) yang bergerak di bidang jasa kurir, logistik, dan transaksi keuangan.

Masyarakat pengguna jasa pos sangat setia memanfaatkan layanan pos (www.bumn.go.id). Namun pesatnya perkembangan teknologi informasi dan komunikasi, perubahan gaya hidup, serta trendi bisnis jasa pos membuat Pos Indonesia mengalami pergeseran bisnis yang sangat signifikan. Dalam transformasi Pos Indonesia memiliki tiga bisnis intinya, yaitu bisnis surat dan paket, bisnis logistik, dan bisnis jasa keuangan. Kendati volume pengiriman surat individu tengah menurun, namun volume pengiriman surat bisnis dan kiriman korporasi terus meningkat. Sumber pendapatan terpenting lainnya adalah jasa pembayaran, jasa pengiriman uang, dan pengiriman paket. Kinerja karyawan PT. Pos Indonesia (Persero) Bengkulu 38000 yang di lihat dari kualitas pelayanan yang diberikan kepada masyarakat penguna jasa pos cukup baik, kerena pelayanan telah menerapakn SOP yang ada di PT.Pos Indonesia (Persero) Bengkulu 38000, walaupun kualitas pelayanan sudah cukup baik kerja di PT. Pos Indonesia (Persero) Bengkulu 38000.

Konflik kerja yang terjadi di PT.Pos Indonesia (Persero) Bengkulu 38000, terlihat dari kemampuan kerja karyawan PT.Pos Indonesia (Persero) Bengkulu 38000 yang bersaing antar rekan kerja untuk meraih prestasi di PT.Pos Indonesia (Persero) Bengkulu 38000. Sedangkan stres kerja yang terjadi pada karyawan PT. Pos Indonesia (Persero) Bengkulu 38000, adanya karyawan yang sulit berkonsentrasi dalam bekerja yang disebabkan beban kerja yang banyak sehingga sulitnya tidur pada malam hari, sehingga dalam bekerja sering marah-marah, dan menyalahi orang lain dan mudah bermusuhan dengan orang lain.

Berdasarkan uraian tersebut diatas, maka peneliti tertarik untuk melakukan penelitian pengaruh konflik kerja dan stres kerja terhada kinerja karyawan PT Pos Indonesia (Persero) Bengkulu 38000. Penelitian ini bertujuan untuk menjelaskan Konflik Kerja, dan Stres Kerja, dan untuk menjelaskan pengaruh variabel Konflik Kerja (X1) dan Stres Kerja (X2) terhadap Kinerja karyawana (Y) baik secara simultan maupun parsial. 


\section{TINJAUAN PUSTAKA}

\section{Kinerja}

Kinerja yang baik merupakan suatu langkah untuk menuju tercapainya tujuan organisasi. Oleh karena itu, kinerja juga merupakan sarana penentu dalam pencapaian tujuan organisasi sehingga perlu diupayakan untuk meningkatkan kinerja karyawan. Kinerja adalah hasil kerja secara kualitas dan kuantitas yang di capai seorang karyawan dalam melaksanakan tugasnya sesuai dengan tanggung jawab yang diberikan kepadanya (Mangkunegara, 2007).

\section{Konflik kerja}

Setiap saat konflik dapat saja muncul, baik antar individu maupun antar kelompok dalam suatu organisasi. Banyak pengertian tentang konflik kerja yang dapat diberikan oleh para ahli untuk merumuskan suatu teori tentang konflik kerja itu sendiri. Hal ini tergantung pada sudut pandang yang digunakan dan persepsi para ahli tersebut tentang konflik kerja. Menurut Rivai (2011), konflik kerja adalah ketidak sesuaian antara dua atau lebih anggota atau kelompok dalam suatu organisasi atau perusahaan yang harus membagi sumber daya yang terbatas karena mereka mempunyai perbedaan status, tujuan, dan nilai yang berbeda.

\section{Stres Kerja}

Stres kerja menurut Mangkunegara (2008) adalah sebuah perasaan tertekan yang di alami karyawan dalam menghadapi pekerjaan. Stres kerja ini tampak dari sikap, antara lain emosi tidak stabil, perasaan tidak tenang, suka menyendiri, sulit tidur, merokok yang berlebihan, tidak bisa rileks, cemas, tegang, gugup, tekanan darah meningkat, dan mengalami gangguan pencernaan. Menurut Robbins dalam Benyamin Molan (2006) menyatakan stress kerja adalah kondisi yang muncul dari interaksi antara manusia dan pekerjaan serta di karakteristik oleh perubahan manusia yang memaksa mereka untuk menyimpang dari fungsi normal.

\section{METODE PENELITIAN}

\section{Jenis Penelitian}

Penelitian ini merupakan penelitian kuantitatif. Data yang dikumpulkan merupakan data kualitatif yang di angkakan. Metode penelitian kuantitatif dapat diartikan sebagai sebagai metode penelitian yang berlandaskan pada 
filsafat positiveness, digunakan untuk meneliti pada populasi atau sampel tertentu, pengumpulan data menggunakan instrument penelitian, analisis data bersifat kuantitatif atau statistik, dengan tujuan untuk menguji hipotesis yang telah ditetapkan (Sugiyono, 2013).

\section{Sumber Data}

Data yang digunakan dalam penelitian ini merupakan data primer yang diperoleh langsung dari tanggapan responden terhadap pernyataan. Data primer adalah data yang diperoleh secara langsung meliputi dokumen dokumen perusahaan berupa sejarah perkembangan perusahaan, struktur organisasi dan lain-lain yang berhubungan dengan penelitian (Sugiyono 2013).

\section{Jenis Data}

Data yang digunakan dalam penelitian ini merupakan data primer yang diperoleh langsung dari tanggapan responden terhadap pernyataan yang ada di kuesioner yang diberikan kepada seluruh karyawan PT.Pos Indonesia (Persero) Bengkulu 38000. Selain data primer, penelitian ini juga menggunakan data sekunder yang didapat dari PT.Pos Indonesia (Persero) Bengkulu 38000 berupa data karyawan dan buku profil PT.Pos Indonesia (Persero) Bengkulu 38000 Bengkulu.

\section{Populasi dan Sampel}

Populasi adalah wilayah yang memiliki objek/ subjek yang berkualitas dan karakteristik tertu yang ditetapkan oleh peneliti untuk dipelajari dan kemudian ditarik kesimpulannya (Sugiyono,2013) Adapun populasi dalam penelitian ini adalah sejumlah karyawan PT Pos Indonesia Bengkulu 38000 .

\section{Uji Validitas}

Uji validitas adalah uji yang digunakan untuk menunjukkan sejauh mana alat ukur yang digunakan dalam menyatakan alat yang digunakan untuk mengukur sah, atau valid tidaknya suatu kuesioner antara data yang terkumpul dengan data objek yang di teliti (Sugiyono, 2013). Pengujian ini menggunkan program SPSS 16.0 for windows. Alat ukur dinyatakan valid jika skor pernyataan yang telah disusun berkorelasi positif dengan skor totalnya dan peluang ralat maksimalnya lebih besar dari 0,05 (Ghozali,2012). Keputusan pengujian validitas instrument dapat menggunakan taraf signifikansi 5\% $(0,05)$ dan sesuai dengan r-tabel untuk sampel 103 yaitu 0,195 . 


\section{Uji Reliabilitas}

Uji realibilitas dilakukan untuk mengetahui kehandalan atau sejauh mana hasil pengukuran tetap konsisten bila dilakukan pengukuran beberapa kali terhadap masalah yang sama. Uji realibilitas untuk mengetahui konsistensi alat ukur apakah alat pengukur yang digunakan dapat diandalkan dan tetap konsisten jika pengukuran tersebut diulang. Suatu kuesioner dinyatakan reliabel atau handal jika jawaban seseorang stabil dari waktu ke waktu.(Ghozali, 2012).uji reliabilitas digunakan untuk menguji sejauh mana suatu hasil pengukuran dapat di percaya. SPSS 16 for windows memberikan fasilitas unutk mengukurreliabilitas dan uji statistik Cronbanch's Alpha $(\alpha)$, yaitu suatu variabele dikatakan reliabel jika memiliki nilai lebih besar dari Cronbanch's Alpha $\alpha>0.60$ (Ghozali, 2012).

\section{HASIL PENELITIAN}

\section{Analisis Linier Berganda}

Untuk proses pengolahan data adalah dengan menggunakan analisis regresi linier berganda, karena analisis ini dapat digunakan untuk mengetahui pengaruh lebih dari satu variabel bebas terhadap satu variabel terikat yaitu antara Konflik Kerja (X1) dan Stres Kerja (X2) terhadap kinerja karyawan (Y). Berdasarkan hasil perhitungan regresi linier berganda dengan menggunakan program SPSS ver.16 for windows, maka diperoleh hasil sebagai berikut: Tabel Analisis Regresi Linier Berganda

Coefficients ${ }^{\mathrm{a}}$

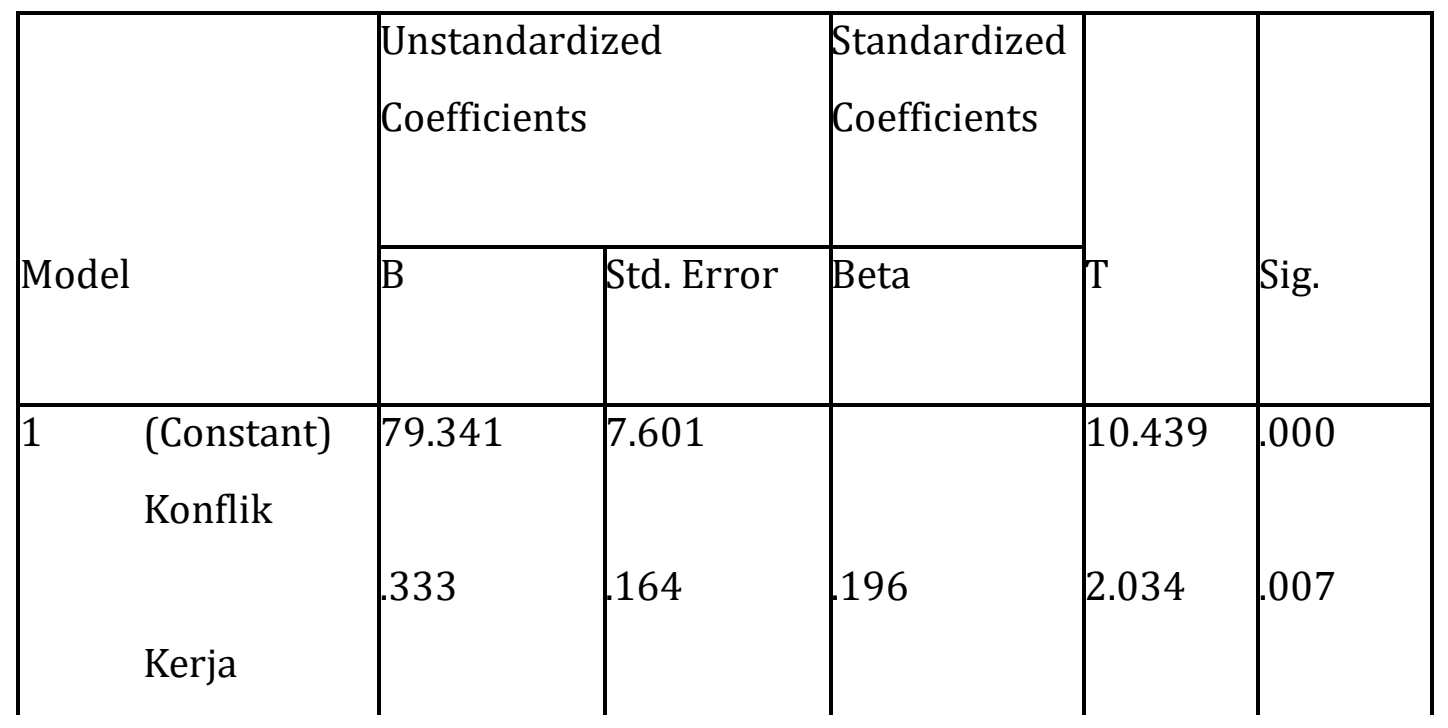


\begin{tabular}{|l|l|l|l|l|l|} 
Stres Kerja & -.315 & 100 & -.165 & -1.108 & .029 \\
\hline
\end{tabular}

a. Dependent Variable: Kinerja Karyawan

Sumber: Hasil Data yang diolah 2018

Berdasarkan Tabel Analsis Regresi Linier Berganda diatas dapat diketahui persamaan regresi linear berganda diatas, maka dapat disimpulkan sebagai berikut :

$Y=79.341+0,333 \times 1-0,315 \times 2$

Berdasarkan persamaan diatas, maka dapat ditentukan sebagai berikut :

1. Nilai konstanta (a) sebesar 79,341 menujukan bahwa konflik kerja (X1) dan stress kerja (X2) cenderung tetap (nol), maka kinerja karyawan (Y) PT. Pos Indonesia (Persero) Bengkulu 38000 akan konstan sebesar 79,341.

2. Nilaikoefisienregresi (b1) sebesar 0,333 yang berartimenunjukkan bahwa jika konflik kerja (X1) karyawan PT. Pos Indonesia (Persero) Bengkulu 38000 berpengaruh positif terhadap kinerja. Artinya apabila konflik kerja tinggi maka kinerja karyawan akan meningkat atau tinggi.

3. NilaiKoefisienregresi (b2) sebesar -0,315 yang berartimenunjukkan bahwa jikaStreskerja (X2 karyawan PT. Pos Indonesia (Persero) Bengkulu 38000 berpengaruh negatif terhadap kinerja. Artinya apabila stres kerja rendah, makakinerjakaryawanakanmeningkatatautinggi.

\section{Uji F (Uji Simultan)}

Uji F (Uji Simultan) dilakukan untuk menguji pengaruh variabel konflik kerja dan stres kerja secara bersama-sama terhadap kinerja karyawan PT.Pos Indonesia (Persero) Bengkulu 38000. Uji F pada dasarnya menunjukan apakah semua variabel independen yang dimasukan mempunyai pengaruh secara simultan terhadap variabel dependen. Pengambilan keputusan dilakukan dengan melihat nilai pada taraf signifikan 5\%. 
ANOVA

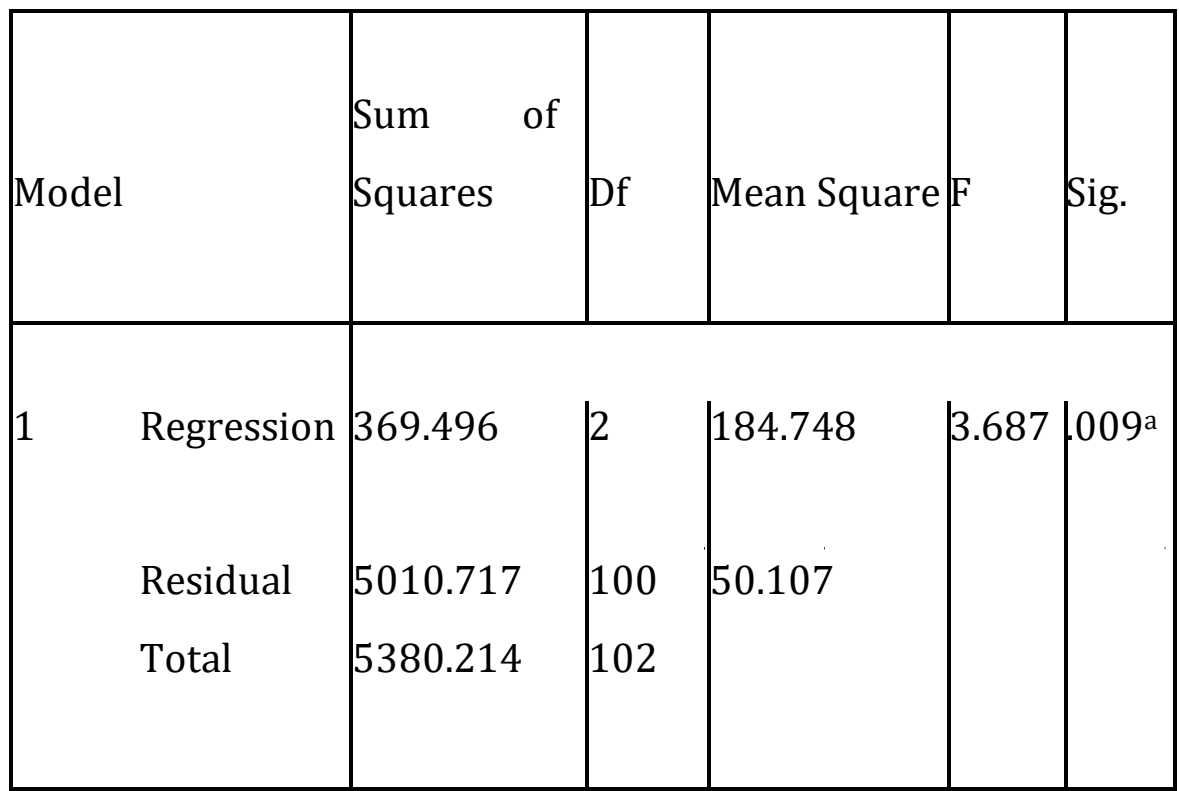

a. Predictors: (Constant), Stres Kerja, Konflik Kerja

b.DependentVariable:KinerjaKaryawan

Dari analisis yang dilakukan seperti yang di tunjukkan pada Tabel 4.6 diperoleh hasil bahwa signifikasi sebesar 0,009 $<0,05$ yang berarti bahwa Ho ditolak dan Ha diterima. Dengan demikian dapat disimpulkan bahwa variabel konflik kerja dan stres kerja secara simultan berpengaruh terhadap kinerja Karyawan PT.Pos Indonesia (Persero) Bengkulu 38000, yang berarti bahwa kedua variabel independent memiliki pengaruh positif dimana jika kedua variabel semakin tinggi maka akan mempengaruhi kinerja karyawan PT.Pos Indonesia (Persero) Bengkulu 38000. Hal ini menjawab hipotesis yang pertama konflik kerja dan stres kerja berpengaruh terhadap kinerja Karyawan PT.Pos Indonesia (Persero) Bengkulu 38000.

\section{Uji t (Uji Parsial)}

Uji t dilakukan untuk menguji pengaruh variabel konflik kerja dan stres kerja secara parsial terhadap kinerja karyawan PT.Pos Indonesia (Persero) Bengkulu 38000. Pengambilan keputusan dilakukan dengan melihat nilai pada taraf signifikan 5\%. Berdasarkan hasil diatas, didapat nilai variabel konflik kerja, bahwa nilai signifikan variabel konflik kerja yaitu sebesar 0.07 $<0.05$ yang berarti maka Ho ditolak dan Ha diterima, sehingga dapat disimpulkan bahwa terdapat pengaruh positip signifikan antara variabel konflik kerja terhadap kinerja karyawan PT.Pos Indonesia (Persero) 
Bengkulu 38000. Hal ini menjawab hipotesis kedua yaitu konflik kerja berpengaruh terhadap kinerja karyawan PT.Pos Indonesia (Persero) Bengkulu 38000.

Sedangkan untuk nilai signifikan variabel stres kerja yaitu sebesar $0.029<$ 0.05 yang berarti maka Ho ditolak dan Ha diterima, sehingga dapat disimpulkan bahwa secara signifikan stres kerja mempunyai pengaruh negatif terhadap kinerja karyawan PT.Pos Indonesia (Persero) Bengkulu 38000. Hal ini menjawab hipotesis ketiga yaitu stres kerja berpengaruh terhadap kinerja karyawan PT.Pos Indonesia (Persero) Bengkulu 38000.

\section{PEMBAHASAN HASIL PENELITIAN}

\section{Pengaruh Konflik Kerja dan Stres Kerja Terhadap Kinerja Karyawan}

Hasil penelitian hipotesis pertama secara simultan diperoleh data bahwa konflik kerja dan stress kerja berpengaruh secara positif dan signifikan terhadap kinerja karyawan PT. Pos Indonesia (Persero) Bengkulu 38000 sehingga hipotesis pertama diterima. Hasil penelitian ini sesuai dengan teori yang dikemukakan oleh Robbins (2008) bila konflik fungsional yang terjadi didalam sebuah instansi, maka akan berdampak pada kinerja karyawan. Namun bila konflik disfungsional yang terjadi, maka akan menurunkan kinerja karyawan. Sedangkan stres kerja berpengaruh terhadap kinerja karyawan, bila stres kerja yang terjadi didalam sebuah intasnsi bersifat positif yang disebut eustres untuk dapat menyelesaikan masalah-masalah yang dihadapinya, meningkatkan kinerja dan lain-lain. Sebaliknya,bila stres kerja yang bersifat negatif disebut distress, maka akan berdampak pada penurunan kinerja karyawan. Hasil penelitian ini juga didukung oleh M.Rosidhan ,Ika Ruhana.dkk. (2016) dimana Pengaruh Konflik kerja dan stress kerja terhadap kinerja karyawan Pt.Telkomsel malang bahwa terdapat pengaruh negative dan signifikan antara variabel Konflik Kerja dan variabel Stres Kerja terhadap variabel Kinerja Karyawan.

\section{Pengaruh Konflik Kerja Terhadap Kinerja Karyawan}

Hasil penelitian hipotesis kedua yaitu konflik kerja mempunyai pengaruh positif dan signifikan terhadap kinerja karyawan PT. Pos Indonesia (Persero) Bengkulu 38000. Apabila terjadi peningkatan terhadap konflik kerja yang dialami oleh karyawan, maka akan berdampak pada peningkatan kinerja 
karyawan PT.Pos Indonesia (Persero) Bengkulu 38000. Secara teori penelitian ini mendukung oleh Robbins ( 2004) Konflik dapat mempunyai dampak positif atau negatif terhadap kinerja suatu perusahaan, tergantung pada sifat konflik dan bagaimana konflik itu dikelola.Hasil penelitian ini juga didukung oleh Gabreila Wenur (2018) dimana hasi penelitiannya, menunjukkan bahwa variable konflik kerja memiliki pengaruh yang positif dan signifikan terhadap tinggirnya Kinerja karyawan pada Bank BNI 46 Cabang Manado.

\section{Pengaruh Stres Kerja Terhadap Kinerja Karyawan}

Hasil penelitian hipotesis ketiga yaitu stres kerja yang mempunyai pengaruh negatife dan signifikan terhadap kinerja karyawan PT. Pos Indonesia (Persero) Bengkulu 38000. Berdasarkan hasil dari penelitian ini artinya, jika stres kerja meningkat maka kinerja akan menurun atau rendah. Begitu juga sebaliknya bila stres kerja rendah maka kinerja karyawan PT. Pos Indonesia (Persero) Bengkulu 38000 akan meningkat.

Secara teori penelitian ini mendukung oleh Robbins (2008), menyatakan bahwa terdapat pengaruh yang erat antara stres dengan kinerja. Pada tahapan tertentu stres akan meningkatkan kinerja karyawan, namun dengan semakin tinggi tingkatan stres akan berdampak pada menurunnya kinerja karyawan.Hasil penelitian ini didukung oleh Wilian (2016) Stres Kerja memberikan pengaruh negatif dan signifikan terhadap kinerja karyawan PT.Cahaya Kalbar Tbk Pontianak .

\section{KESIMPULAN DAN SARAN}

\section{Kesimpulan}

Penelitian ini bertujuan untuk membuktikan pengaruh konflik kerja dan stres kerja terhadap kinerja karyawan PT.Pos Indonesia (Persero) Bengkulu 38000. Berdasarkan hasil analisis data dan pengujian hipotesis, maka dapat ditarik kesimpulan bahwa:

1. Secara bersama-sama (simultan) konflik kerja dan stres kerja berpengaruh positif dan signifikan terhadap kinerja karyawan PT.Pos Indonesia Bengkulu 38000, artinya jika terjadi konflik kerja dan stres kerja yang terjadi pada karyawan PT.Pos Indonesia Bengkulu 38000 akan 
mempengaruhi kinerja karyawan PT.Pos Indonesia Bengkulu 38000, maka dari itu semakin tinggi konflik kerja dan stres kerja yang terjadi antar karyawan, maka akan membuat kinerja karyawan semakin baik pula.

2. Konflik kerja berpengaruh positif dan signifikan terhadap kinerja karyawan PT.Pos Indonesia (Persero) Bengkulu 38000, yang berarti bahwa konflik kerja yang terjadi akan meningkatkan kinerja karyawan PT.Pos Indonesia (Persero) Bengkulu 38000.

3. Stres kerja berpengaruh negatif dan signifikan terhadap kinerja karyawan PT.Pos Indonesia (Persero) Bengkulu 38000, yang berarti bahwa stres kerja yang rendah akan meningkatkan kinerja karyawan PT.Pos Indonesia (Persero) Bengkulu 38000.

\section{Saran}

Berdasarkan hasil penelitian yang dilakukan, Saran yang dapat diberikan dari penelitian ini adalah:

1. Sebaiknya PT.Pos Indonesia (Persero) Bengkulu 38000 dalam meningkatkan kinerja karyawan melalui konflik kerja dan stres kerja yang terjadi terhadap kinerja karyawan PT.Pos Indonesia (Persero) Bengkulu 38000, perlu dipertahankan karena terbukti bahwa konflik kerja dan stres kerja yang terjadi dapat meningkatkan kinerja karyawan PT.Pos Indonesia (Persero) Bengkulu 38000 kuatitas, kualitas, kreatifitas, dan hubungan kerja serta dapat menyikapi pekerjaan dengan baik sehingga dapat memberikan pelayanan yang baik kepada masyarakat.

2. Dengan terbuktinya pengaruh konflik kerja terhadap kinerja karyawan . secara langsung konflik kerja yang yang terjadi di antara karyawan dapat menunjang kinerja karyawan PT.Pos Indonesia (Persero) Bengkulu 38000. Hal ini patut dipertahankan agar setiap karyawan dapat mencapai kinerja yang baik, yang mana hal ini juga dapat memberikan dampak pada masyarakat pengguna PT.Pos Indonesia (Persero) Bengkulu 38000 .

3. Perlu dilakukannya pendekatan-pendekatan terhadap para karyawan PT.Pos Indonesia (Persero) Bengkulu 38000, agar stres yang dialami seperti selisih paham antara saya dan rekan kerja, menjadi tidak berkepanjangan dan tidak berdampak buruk bagi karyawan PT.Pos Indonesia (Persero) Bengkulu 38000. 


\section{DAFTAR PUSTAKA}

Ade Florent S. (2010). "Pengaruh Manajemen Konflik Terhadap Kinerja KarywanpadaKaryawan PT. PLN (PERSERO) Cabang Medan”. Skripsi tidak diterbitkan. FakultasEkonomi Univesitas Sumatra Utara.

Alex S. Niti sememito.1996.Manajemen Personalia,Jakarta: Graha Indonesia

Ghozali,Imam.2012.Aplikasi Analisis Multivariate dengan program SPS Semarang; Universitas Diponogoro

Gabreila Wenur,2018. The Effect Of Conflict And Work Stres On Employees Performance Of PT.Bank Negara Indonesia (Persero) tbk, Jurnal EMBA Vol.6 No.1 Januari 2018, Hal.51-60, Universitas Sam Ratulangi Manado

Handoyo, S. 2001. Stres Pada Masyarakat Surabaya. Jurnal Insan Media Psikologi Surabaya:

Fakultas Psikologi Universitas Airlangga. Vol. 3, No.12, Hal 61-74

Handoko, H (2008). Manajemen Personalia dan Sumber Daya Manusia. BPFE Yogyakarta.

Hendrikus Wiliam.2016. Teknik Elektro, Fakultas Teknik, Universitas Tanjungpura Pengaruh Stres Kerja Terhadap Kinerja Karyawan Bagian produksi di PT.Cahaya Kalbar Tbk Pontianak.

M.Rosidhan ,Ika Ruhana.dkk.Pengaruh Konflik kerja dan stress kerja terhadap karyawan Pt.Telkomsel malang.Universitas Brawijaya, Malang Jurnal Administrasi Bisnis (JAB)|Vol. 41 No.1 Desember 2016.

Mangkunegara, A.A. Anwar Prabu.2000. Manajemen Sumber Daya ManusiaPerusahaan.Remaja Rosda Karya, Bandung.

Sastrohadiwiryo, siswanto.2011. Manajemen Tenaga Kerja Indonesia pendekatan Administrasi dan Operasional.Penerbit Bumi Aksara, Jakarta.

Sugiyono. 2013. Metode penelitian kuantitatif,kualitatif dan $R \& D$, cetakan ke delapan belasAlfabeta, Bandung

Rivai, Veitzhal.2011.Manajemen Sumber Daya Manusia Untuk Perusahaan Dari. Teori KePraktek. PT. Rajagrafindo Persada: Jakarta

Robbins, Waltondan Dutton(1992, 1999: 231). Perilaku Organisasi dan Pesikologi Pesonalia, Jakarta : PT. Rineka Cipta. .2006. Perilaku Organisasi. PT Indeks, Kelompok Gramedia, Jakarta.

. 2008. Manajemen Sumber Daya Manusia, Rajawali Press, Jakarta 